\title{
Therapist Interventions and Client Innovative Moments in Emotion-Focused Therapy for Depression
}

\author{
Carla Cunha \\ Instituto Superior da Maia/Centro de Investigação do Núcleo de \\ Estudos e Intervenção Cognitivo-Comportamental, Maia, \\ Portugal
}

\author{
Clara E. Hill \\ University of Maryland
}

\author{
Miguel M. Gonçalves \\ University of Minho
}

\author{
Inês Mendes \\ Instituto Superior da Maia/Centro de Investigação do Núcleo de \\ Estudos e Intervenção Cognitivo-Comportamental, Maia, \\ Portugal
}

\author{
António P. Ribeiro and Inês Sousa \\ University of Minho \\ Lynne Angus and Leslie S. Greenberg \\ York University
}

\begin{abstract}
According to the narrative approach, change in self-narratives is an important part of successful psychotherapy. In this view, several authors have highlighted the usefulness of narrating new experiences (like actions, thoughts, and stories) during therapy in contrast with maladaptive client self-narratives. These new experiences are termed here innovative moments (IMs), and different types can be specified: action, reflection, protest, reconceptualization, and performing change. With the aim of understanding which therapist skills are related to client IMs, we analyzed the association between exploration, insight, and action skills and IMs in two initial, two middle, and two final sessions of three good outcome (GO) and three poor outcome (PO) cases of emotion-focused therapy (EFT) for depression. IMs occurred more often in GO than PO cases. Furthermore, in GO more than PO cases, exploration and insight skills more often preceded action, reflection, and protest IMs in the initial and middle phases of EFT, but more often preceded reconceptualization and performing change IMs in the final phase. Action skills were more often associated with action, reflection, and protest IMs across all phases, especially in the final phase, of GO EFT.
\end{abstract}

Keywords: innovative moments, therapist interventions, helping skills, emotion-focused therapy

Recently, several therapists have been acknowledging the occurrence and potential usefulness of facilitating narrative change in emotion-focused therapy (EFT) (e.g., Angus \&

This article was published Online First June 25, 2012.

Carla Cunha, Department of Social and Behavioral Sciences, Instituto Superior da Maia/Centro de Investigação do Núcleo de Estudos e Intervenção Cognitivo-Comportamental (ISMAI/CINEICC), Maia, Portugal; Miguel M. Gonçalves and António P. Ribeiro, School of Psychology, University of Minho, Braga, Portugal; Clara E. Hill, Department of Psychology, University of Maryland; Inês Sousa, Department of Mathematic, University of Minho and Department of Social and Behavioral Sciences, ISMAI/CINEICC; Lynne Angus and Leslie S. Greenberg, Department of Psychology, York University, Toronto, Ontario, Canada.

This article was supported by the Portuguese Foundation for Science and Technology (FCT), by the Grant PTDC/PSI/72846/2006 (Narrative Processes in Psychotherapy, 2007-2010) and by the PhD Grant SFRH/BD/ $30880 / 2006$. The authors are grateful to all the judges at ISMAI that collaborated in this study through the coding of sessions.

Correspondence concerning this article should be addressed to Miguel M. Gonçalves, School of Psychology, University of Minho, 4710 Braga, Portugal. E-mail: mgoncalves@psi.uminho.pt
Greenberg, 2011; Greenberg \& Angus, 2004), and researchers have demonstrated how these narrative novelties develop (e.g., Mendes et al., 2010, 2011), as well as how changes in autobiographical memory demonstrated by client narratives accompany the experiential changes taking place in EFT (Boritz, Angus, Monette, \& Hollis-Walker, 2008, 2011). What has not yet been demonstrated, however, is the role that therapists have in facilitating the narrative change process of their clients. Hence, we investigated how therapist exploration, insight, and action skills are associated with changes in narratives (i.e., new experiences, actions, thoughts, and narratives about the self, here termed innovative moments [IMs]).

\section{Narrative Change and IMs in Psychotherapy}

According to a narrative framework of therapy (e.g., White \& Epston, 1990; White, 2007), clients seek help when they feel overwhelmed by their life difficulties and have lost the ability to flexibly create meanings outside the scope of problematic self-narratives. These problematic self-narratives can be disorganized and nonspecific, lacking a coherent sense of personal agency (Boritz et al., 2008; Botella, Herrero, Pacheco, \& Cor- 
bella, 2004), or can highlight hurtful experiences, demonstrating a bias toward negative events on autobiographical recall (Boritz et al., 2008, 2011). Therefore, several authors have emphasized the importance of encouraging client elaboration of new stories or narrative novelties in psychotherapy as a way of articulating changes that are accomplished in a coherent narrative account and facilitating the development of new selfnarratives (Angus \& McLeod, 2004; Dimaggio, Salvatore, Azzara, \& Catania, 2003; Gonçalves, Matos, \& Santos, 2009; Gonçalves \& Stiles, 2011; Levitt, Korman \& Angus, 2000; White \& Epston, 1990).

Narrative change was initially emphasized only within the context of narrative therapies. However, more recently, other researchers, particularly those in EFT, have acknowledged the usefulness of facilitating client narrative changes as a way of structuring and consolidating other changes (e.g., the symbolization of new emotions or emotional change) and facilitating narrative reconstruction of the self during psychotherapy (e.g., Angus \& McLeod, 2004; Angus \& Greenberg, 2011). These narrative changes usually refer to new actions, thoughts, and personal stories that appear and are articulated during therapy as novel experiences that contrast with the former usual client difficulties (and problematic self-narratives). These narrative novelties are termed as innovative moments.

In several studies, five types of IMs have been observed and reliably identified through the Innovative Moments Coding System (IMCS; Gonçalves, Matos, \& Santos, 2009; Gonçalves, Ribeiro, Mendes, Matos, \& Santos, 2011): action, reflection, protest, reconceptualization, and performing change (see Table 1 for definitions and examples).

Previous studies have shown that IMs occur more often in good outcome (GO) than poor outcome (PO) cases (Matos, Santos, Gonçalves, \& Martins, 2009; Mendes et al., 2010; Gonçalves et al., in press), providing evidence for the usefulness of the IMCS in the discrimination of productive and unproductive narrative changes in different outcome groups. Findings emerging in studies with narrative therapy (NT; Matos et al., 2009) and EFT (Mendes et al., 2010) suggest that although action, reflection, and protest IMs occurred in both GO and PO groups, reconceptualization and performing change occurred more often in GO than in PO cases. The same findings (except that performing change IMs occurred equally in both GO and PO cases) were found in client-centered therapy (CCT), (Gonçalves et al., in press). These findings suggest that reconceptualization and performing change IMs are particularly specific to GO psychotherapy (Gonçalves et al., in press; Matos et al., 2009; Mendes et al., 2010).

Based on these findings, Gonçalves et al. (2009) developed a heuristic model that describes the sequential nature of IMs in psychotherapy. They suggested that action, reflection, and protest IMs emerge first and challenge the problematic self-narrative. These three types of IMs occur interactively, such that each fuels the others. In GO cases, reconceptualization IMs begin to appear in the middle phase of therapy and continue as the dominant type until the end. Finally, performing change IMs emerge and expand into the future the changing self-narrative.

Although it makes sense that therapists facilitate IMs, we have no empirical evidence for what therapist behaviors are associated with IMs, and whether different therapeutic skills are associated with different types of IMs. Knowing more about whether and which specific therapist skills are associated with
IMs would have implications for training therapists in the facilitation of narrative change in EFT, so research is clearly needed on this topic.

\section{Therapist Skills in Psychotherapy}

Some of the earliest process research in the 1940s (e.g., Snyder, 1945 ) involved the categorization of therapist skills (also known as verbal response modes), and the popularity of this line of research led to the elaboration of more than 30 different category systems (e.g., Elliott et al., 1987; Hill, 1978; Stiles, 1979). It certainly makes sense to capture what therapists overtly do during sessions as one way of characterizing the therapist contribution to psychotherapy (Goldfried \& Davila, 2005). Empirical research has shown, for instance, that therapists from different theoretical orientations used skills differently (e.g., Hill, Thames, \& Rardin, 1979; Stiles, Shapiro, \& Firth-Cozens, 1989) and that specific skills were associated with the establishment of an empathic therapeutic alliance (Barkham \& Shapiro, 1986; Fitzpatrick, Stalikas, \& Iwakabe, 2001).

From the several alternatives for the categorization of therapist skills, the Helping Skills System (HSS; Hill, 2009) has been one of the most widely used (Hill, Nutt, \& Jackson, 1994). In this pantheoretical system, the assumption is made that different skills are used across three therapy phases: an initial phase focused on the exploration of client problems and difficulties (exploration stage); a middle phase focused on the promotion of insight (insight stage); and a final phase focused on the facilitation of changes in action (action stage). Exploration skills involve approval and reassurance, closed and open questions, restatements, and reflection of feelings; insight skills involve challenges, interpretations, self-disclosure, and immediacy; and action skills involve information and direct guidance (see Table 2 for definitions and examples).

Although this system has been widely used in the study of different therapy models and training (e.g., Hill \& Kellems, 2002; Hill \& Lent, 2006; Hill et al., 1979), a special issue of Psychotherapy in 2005 dedicated to the interplay of therapist techniques and the therapeutic relationship edited by Gelso (2005) pointed out the need to promote more research within this framework in humanistic and experiential perspectives, such as EFT. According to a research review on response modes carried out by Elliott, Greenberg, and Lietaer (2004), most of the studies within the humanistic and experiential modalities used demonstration sessions or one-time interviews, not sessions from different phases of actual therapy. Furthermore, other studies focused less on complete sessions and more on specific in-session moments (such as when humanistic/experiential therapists use interpretation) and how these relate to immediate client changes (e.g., Gazzola \& Stalikas, 1997, 2004). Therefore, studies in the use of therapist skills might facilitate the understanding of the therapy processes in these modalities, more specifically in EFT.

\section{Purpose of the Present Study}

In the present study, we set out to investigate the connection between therapist skills and client IMs within the initial, middle, and final phases of GO and PO cases of EFT for depression using a microanalytic sequential process design (Elliott, 1985, 2010). In this study, we build upon a previous study (Mendes et al., 2010) 
Table 1 A Brief Depiction of the Five Types of IMs With Examples From EFT Cases

\begin{tabular}{|c|c|}
\hline Types of IMs & Examples from EFT (problematic narrative: depression) \\
\hline \multicolumn{2}{|c|}{$\begin{array}{l}\text { Action IMs } \\
\text { cted } \quad \text { C: I actually took a step the other night and I let my husband know that I } \\
\text { ve. } \\
\text { thought that my workload was a lot more that his was and that we should } \\
\text { share our things more evenly. }\end{array}$} \\
\hline \multicolumn{2}{|c|}{ Reflection IMs } \\
\hline $\begin{array}{l}\text { Reflection IMs refer to new understandings or thoughts that } \\
\text { undermine the dominance of the problematic self-narrative. } \\
\text { They can involve a cognitive challenge to the problem or } \\
\text { cultural norms and practices that sustain it or new insights } \\
\text { and understandings about the problem or problem } \\
\text { supporters. These IMs frequently can also assume the form } \\
\text { of new perspectives or insights upon the self while relating } \\
\text { to the problem, which contradict the problematic self- } \\
\text { narrative. }\end{array}$ & $\begin{array}{l}\text { C: Yeah, because I think that this still affects me now a lot of times . . Like I } \\
\text { don't really have the courage to come forward with things because I just } \\
\text { expect not being heard or people not to being able to relate to it or understand } \\
\text { it. So, rather than trying, I'm just so afraid of getting the same treatment, the } \\
\text { rejection that I just remain in the same mode I constructed back then. } \\
\text { T: Right, so it's almost a general thing now-that's how you were treated then } \\
\text { and now it's almost an expectation that that's how you'll be treated now? } \\
\text { C: Yeah. }\end{array}$ \\
\hline
\end{tabular}

Protest IMs involve moments of critique, confrontation or antagonism toward the problem and its specifications and implications or people that support it. They can be directed at others or at the self. Oppositions of this sort can either take the form of actions (achieved or planned), thoughts or emotions, but necessarily imply an active form of resistance, repositioning the client in a more proactive confrontation to the problem (which does not happen in the previous action and reflection IMs). Thus, this type of IMs entails two positions in the self: one that supports the problematic self-narrative and another that challenges it. These IMs are coded when the second position acquires more power than the first.
Protest IMs

C: I don't like you gambling your money, because you work hard for it. I want you to put an effort on trying to solve your problems instead of just shoving them under the carpet or denying it.

T: I want you to look at your problems.

C: Yeah, I want you to look at your problems, I believe I'm doing my part and I want you to do yours!

T: What do you feel towards him?

C: There, there is a demand. Umm, I'm angry with him.

T: Tell him about being angry.

C: Yeah, I'm mad at you. I'm mad at you!
Reconceptualization IMs always involve two dimensions: a) a description of the shift between two positions (past and present) and b) the transformation process that underlies this shift. In this type of IMs there is the recognition of a contrast between the past and the present in terms of change, and also the ability to describe the processes that lead to that transformation. In other words, not only is the client capable of noticing something new, but also capable of recognizing oneself as different when compared with the past due to a transformation process that happened in between.
Reconceptualization IMs

C: I've been, you know, just pretty well. Again, I'm more expressing my feelings now towards things, I find...

T: Yeah, that's good.

C: So that's a change for me.

T: Yeah

C: And it feels good after I do that because it's, it's important you know

T: Yeah, you feel good when you do it

C: Yeah, it should be expressed. I shouldn't have to hold all that in me, so that makes me feel more power, you know, more in control of things

T: Yeah. So in general you feel more in control and

C: yeah

T: you're saying it's related to expressing your feelings.

C: That's right, yeah. I've been feeling much less helpless or weak or

T: Hh-huh. You feel stronger when you say what you want.

C: Right, when I when I do that, yeah.
Performing change IMs refer to new aims, projects, activities, or experiences (anticipated or already acted) that become possible because of the acquired changes. Clients may apply new abilities and resources to daily life or retrieve old plans or intentions postponed due to the dominance of the problem.
Performing change IMs

C: . . . but I was able to actually bring up the subject and talk to him about it, as before in the past I was afraid to say something because he " $d$ take it the wrong way, or he"d take it as sort of an attack to him.

T: So you're feeling kind of more freed up, it sounds

C: Yes

T: like to be able to bring up things with him

C: $m m-h m$

T: and talk about things. A lot more, kind of less afraid, less cautious about approaching him.

C: Mm-hm, right.

Note. Adapted from Gonçalves, M. M., Mendes, I., Ribeiro, A., Angus, L., \& Greenberg, L. S. (2010). Innovative moments and change in emotional focused therapy: The case of Lisa. Journal of Constructivist Psychology, 23, 1-28. IMs = Innovative Moments; EFT = emotion-focused therapy. 
Table 2

Examples of Helping Skills in EFT

\begin{tabular}{|c|c|c|c|}
\hline Intervention categories & Helping skills & Description & Examples in EFT \\
\hline \multirow[t]{5}{*}{ Exploration skills } & 1. Approval/reassurance & $\begin{array}{l}\text { Provides simple encouragement, } \\
\text { reinforcement or emotional support. }\end{array}$ & T: I understand. \\
\hline & 2. Closed questions & $\begin{array}{l}\text { Request information/clarification, with a } \\
\text { simple yes or no answer from the client. }\end{array}$ & T: Do you agree with what she said? \\
\hline & 3. Open questions & $\begin{array}{l}\text { Ask clients to elaborate further or to explore } \\
\text { more. }\end{array}$ & T: How are you? \\
\hline & 4. Restatement & $\begin{array}{l}\text { Rephrases what the client said, in regards to } \\
\text { content or meaning, trying to increase } \\
\text { clarity. }\end{array}$ & $\begin{array}{l}\text { T: So going out of the house allows you } \\
\text { to put that aside for the time being. }\end{array}$ \\
\hline & 5. Reflection of feelings & $\begin{array}{l}\text { Rephrases what the client said in terms of } \\
\text { the exploration of feelings or attempts to } \\
\text { identify/infer client's feelings. }\end{array}$ & $\begin{array}{l}\text { T: It seems painful for you to talk about } \\
\text { this situation. }\end{array}$ \\
\hline \multirow[t]{4}{*}{ Insight skills } & 6. Challenge & $\begin{array}{l}\text { Highlights discrepancies, contradictions, } \\
\text { irrational beliefs and conflicts that the } \\
\text { client is unaware of or unwilling to } \\
\text { change. }\end{array}$ & $\begin{array}{l}\text { T: You seem to trivialize this, but a part } \\
\text { of you is feeling resentful. }\end{array}$ \\
\hline & 7. Interpretation & $\begin{array}{l}\text { Goes beyond what the client said and tries to } \\
\text { give/promote other meanings, } \\
\text { explanations, or reasons for behaviors, } \\
\text { thoughts and feelings. }\end{array}$ & $\begin{array}{l}\text { T: So that's where you are then, trying to } \\
\text { understand. / You're the person they } \\
\text { go to. / You're the one who should } \\
\text { accept things and not make a big deal } \\
\text { out of things. / Sounds like, sounds } \\
\text { like that's a lot. / }\end{array}$ \\
\hline & 8. Self-disclosure & $\begin{array}{l}\text { Reveals something personal about the } \\
\text { therapist that transcends the immediate } \\
\text { feelings and the here-and-now of the } \\
\text { therapeutic encounter. }\end{array}$ & $\begin{array}{l}\text { No self-disclosures were found in this } \\
\text { sample. }\end{array}$ \\
\hline & 9. Immediacy & $\begin{array}{l}\text { Specific disclosure of therapist's immediate } \\
\text { feelings and thoughts in relation to the } \\
\text { self, the client, or therapeutic relationship. }\end{array}$ & $\begin{array}{l}\text { T: I also have a lot of admiration for you } \\
\text { because I think you're very strong. }\end{array}$ \\
\hline \multirow[t]{2}{*}{ Action skills } & 10. Information & $\begin{array}{l}\text { Concerns facts or data on the therapy (like } \\
\text { its structure or efficacy) and feedback on } \\
\text { the client. }\end{array}$ & $\begin{array}{l}T: \text { I guess you're aware of forms that } \\
\text { you have to fill after (the session). }\end{array}$ \\
\hline & 11. Direct guidance & $\begin{array}{l}\text { Provides suggestions, instructions, or advice } \\
\text { about the therapeutic process or problem } \\
\text { solving strategies. }\end{array}$ & $\begin{array}{l}\text { T: Tell her how it felt to hear that from } \\
\text { her. }\end{array}$ \\
\hline
\end{tabular}

that showed that IMs evolve along treatment according to the specific pattern in EFT (cf. Mendes et al., 2010, for further detail) described previously. That is, reflection and protest IMs appear in both GO and PO groups (with low presence of action IMs in this specific sample), and reconceptualization and performing change occurred more often in GO than in PO cases (more specifically, performing change IMs are absent in PO EFT cases; see also the model that describes the sequential nature of IMs in psychotherapy in the Introduction of this article). We used the IMs codings of six cases of EFT for depression that Mendes et al. (2010) studied (in that study, all sessions of EFT were coded according to the IMCS) and extended that investigation by examining the therapist dimension (i.e., the use of therapist exploration, insight, and action skills) associated with the IMs. Thus, we investigated (a) how different skills evolve in EFT, (b) whether different skills precede IMs, and finally (c) whether different skills precede different types of IMs.

\section{Method}

\section{Participants}

The cases used for this study were from the York I depression study (Greenberg \& Watson, 1998). Each client in that study was randomly assigned to EFT or CCT and attended 15 to 20 weekly sessions. In the present study, we used the three GO and three PO cases from the EFT sample that were entirely coded for IMs by Mendes et al. (2010). These cases were selected because they had the highest and lowest rates of improvement based on a reliable change index (Jacobson \& Truax, 1991) analysis of the scores obtained with the Beck Depression Inventory (McGlinchey, Atkins, \& Jacobson, 2002). The average Beck Depression Inventory (a 21-item self-report inventory of depressive symptoms; Beck, Steer, \& Garbin, 1988; Beck, Ward, Mendelson, Mock, \& Erbaugh, 1961) scores from pre- to post-therapy were 30.00 ( $S D=$ $5.00)$ to $4.00(S D=1.00)$ for the GO cases and $20.67(S D=4.93)$ to 17.67 ( $S D=4.51)$ for the PO cases. These cases have been used for other published case studies (e.g., Honos-Webb, Surko, Stiles, \& Greenberg, 1999; Honos-Webb, Stiles, \& Greenberg, 2003).

All six clients (four females, two males; five married, one divorced; all Caucasian) met diagnostic criteria for major depression (according to the $D S M-I I I-R$ ). Ages ranged from 27 to 63 years old $(M=45.50, S D=13.78)$, and they completed an average of $17.50(S D=1.87)$ sessions of therapy (see Table 3$)$.

These six cases involved five therapists (four females, one male; four Caucasian, one Indian). The therapists had diverse levels of 
Table 3

Summary of Clients' Information

\begin{tabular}{|c|c|c|c|c|c|}
\hline Clients & Age & Outcome & $\begin{array}{l}\text { Pre-test and post-test } \\
\text { BDI }\end{array}$ & Completed sessions & Sessions analyzed \\
\hline 1 & 27 & GO & 25 to 3 & 15 & $\begin{array}{l}\text { 1, } 2 \text { (initial phase); } \\
\text { 7, } 8 \text { (middle phase); } \\
\text { 14, } 15 \text { (final phase) }\end{array}$ \\
\hline 2 & 34 & GO & 35 to 4 & 18 & $\begin{array}{l}\text { 1, } 2 \text { (initial phase); } \\
9,10 \text { (middle phase); } \\
17,18 \text { (final phase) }\end{array}$ \\
\hline 3 & 48 & GO & 30 to 5 & 16 & $\begin{array}{l}\text { 1, } 2 \text { (initial phase); } \\
8,9 \text { (middle phase); } \\
15,16 \text { (final phase) }\end{array}$ \\
\hline 4 & 63 & $\mathrm{PO}$ & 15 to 13 & 19 & $\begin{array}{l}\text { 1, } 2 \text { (initial phase); } \\
9,10 \text { (middle phase); } \\
18,19 \text { (final phase) }\end{array}$ \\
\hline 5 & 58 & $\mathrm{PO}$ & 23 to 22 & 20 & $\begin{array}{l}\text { 1, } 2 \text { (initial phase); } \\
9,10 \text { (middle phase); } \\
19,20 \text { (final phase) }\end{array}$ \\
\hline 6 & 43 & $\mathrm{PO}$ & 24 to 18 & 17 & $\begin{array}{l}\text { 1, } 2 \text { (initial phase); } \\
\text { 8, } 9 \text { (middle phase); } \\
\text { 16, } 17 \text { (final phase) }\end{array}$ \\
\hline
\end{tabular}

education (from advanced doctoral students to $\mathrm{PhD}$ level clinical psychologists). All therapists participated in a 24-week training in EFT using the manual for the York 1 depression study (Greenberg, Rice, \& Elliott, 1993), which included 8 weeks of training for CCT, 6 weeks for systematic evocative unfolding, 6 weeks for two-chair dialogue, and 4 weeks for empty-chair dialogue training.

The first author (a doctoral-level student in clinical psychology) and six master's level students in clinical psychology coded the therapist skills using the HSS in a sample of sessions coded previously for IMs. All judges (four female, three male) were Portuguese (English speakers as a second language). Only the first author was aware of the outcome status of each case. None of judges were aware of the results of the IMs codings conducted earlier by Mendes et al. (2010).

\section{Measures}

Innovative moments coding system. The IMCS (Gonçalves et al., 2011) includes five mutually exclusive categories: action, reflection, protest, reconceptualization, and performing change (see Table 1). Validity was inferred, given the prior hypothesistesting studies relating process (i.e., presence and evolution of IMs) to outcome (GO and PO) carried out within NT (Matos et al., 2009), CCT (Gonçalves et al., 2011), and EFT (Mendes et al., 2010). These studies established that there were more IMs in GO than PO cases. In addition, action, reflection, and protest IMs were found in both GO and PO cases, whereas reconceptualization occurred significantly more often in GO cases in all the modalities of therapy studied, and performing change occurred more often in GO cases of NT and EFT. IMCS reliability for two coders ranged from .86 in NT (Matos et al., 2009) to .97 for CCT (Gonçalves et al., 2011), which is indicative of strong agreement (Hill \& Lambert, 2004). In the current sample (Mendes et al., 2010), the average kappa between pairs of coders was .89.

Helping skills system. The HSS (Hill, 2009) is a modification of the Hill Counselor Verbal Response Category System (Hill, 1978, 1986). The HSS (see Table 2) is relatively easy to learn and use reliably. It includes 12 nominal, mutually exclusive categories of therapist verbal behavior, which can be organized into the three larger categories of exploration skills (includes approval and reassurance, closed questions, open questions, restatements, and reflections of feelings), insight skills (includes challenges, interpretations, self-disclosure, and immediacy), and action skills (includes information and direct guidance). Therapist statements that are unrelated to therapy or client's problems or issues (e.g., salutations or small talk) are integrated in another category.

Hill (1978) established content validity for the Hill Counselor Verbal Response Category System by combining categories from existing measures and having experts from different theoretical orientations determine the representativeness of categories. Concurrent validity was established through high associations with similar categories on other response mode systems (Elliott, Hill, Stiles, Mahrer, \& Margison, 1987). For the current version of the HSS, an average kappa of .91 between pairs of judges was reported by Hess, Knox, and Hill (2006) for judgments of all response units (i.e., sentences) and .98 by Goates-Jones, Hill, Stahl, and Doschek (2009) for predominant units (the most salient unit within a therapist speaking turn). In the present study, the average kappa between pairs of judges for predominant units was .80 .

\section{Procedures}

In the present study, we selected and used the first two sessions, two sequential middle sessions, and the two final sessions from each of the six cases (Table 3). All these sessions had been coded previously by Mendes et al. (2010) using IMCS, which coded all the sessions from the six cases. In this study, we carried out the codings with the HSS to focus on therapist verbal behavior.

All judges were first trained by the first author to unitize therapist speech into response units (essentially grammatical sentences), using rules adapted by Hill (2009) from Auld and White (1956). This training continued until all the raters reached a minimum of $90 \%$ agreement in the independent unitizing of a session. After training, judges independently unitized all the therapist 
speech in the 36 sessions, attaining an agreement level of $94 \%$. Then, rotating teams of three judges, with the first author serving on all teams, met to reach consensus regarding discrepancies and to then select the predominant unit (defined as the unit that, when compared with the other response units in that therapist turn, has the most impact in the following client response) within speaking turns. Teams used consensus (Hill, Thompson, \& Williams, 1997) to identify the 4991 predominant units.

Once unitizing was completed, the judges were trained, using sessions not included in the present study, by the first author to use the HSS until they reached a minimum kappa of .75 (strong agreement level according to Hill \& Lambert, 2004) between all pairs of judges. The unitizing and coding training took 6 months.

After training, all the therapist units in each session were independently coded into one of the categories of the HSS by rotating teams of three judges. Judgments of two of the three judges were accepted as the master coding; three-way discrepancies were resolved through consensus. For data analyses, we clustered the data into the larger categories of exploration, insight, or action skills (given that some of the more specific categories of the HSS had very low occurrence or did not occur at all). We then divided the skills into those that were used preceding or during IMs versus skills that were used during non-IMs. We took into account the skills used during IMs, assuming that therapist interventions might be related not only to the emergence of client IMs but also expand client elaboration of them. The results concerning non-IMs will not be reported here because our goals were to study innovation rather than noninnovation.

\section{Results}

\section{Therapist Skills Used in EFT}

Table 2 shows examples from the current study for each skill. Table 4 shows the proportions of skills used in the initial, middle, and final phases of GO and PO outcome cases. We analyzed the data clustered into the larger therapist intervention categories of exploration skills, insight skills, and action skills, given that some of the more specific categories of the HSS had very low occurrence or did not occur at all (see Table 4). Thus, results (given later) will be reported only for exploration, insight, and action skills in EFT.

To determine whether there were statistically significant differences in the use of each group of therapist skills in the two outcome groups, we used a multinomial generalized mixed effects model (Agresti, 2002) so that we could estimate the probability of each skill according to therapy phase (initial, middle, final) and type of outcome (GO or PO). We considered type of outcome (GO or PO) as an explanatory variable and assumed that the probability of each skill was a random variable with a Bernoulli distribution. We also included a subject specific random effect to take variability among individuals into account given that we expected that measurements (interventions) from the same participant (therapist) would be correlated.

We then assumed, in accordance with Agresti (2002), that the probability of occurrence of a given skill was a conditional function of type of outcome and therapy phase, where the explanatory

Table 4

Proportion of Therapist Skills Used in EFT

\begin{tabular}{|c|c|c|c|c|c|c|c|c|}
\hline \multirow{3}{*}{$\begin{array}{l}\text { Therapist intervention } \\
\text { categories }\end{array}$} & \multicolumn{4}{|c|}{ Poor outcome } & \multicolumn{4}{|c|}{ Good outcome } \\
\hline & Initial phase & Middle phase & Final phase & Global use & Initial phase & Middle phase & Final phase & Global use \\
\hline & $\%$ & $\%$ & $\%$ & $\%$ & $\%$ & $\%$ & $\%$ & $\%$ \\
\hline \multicolumn{9}{|l|}{ Exploration skills } \\
\hline 1. Approval/reassurance & 5.92 & 3.15 & 3.17 & 4.08 & 2.00 & 1.5 & 4.04 & 3.15 \\
\hline 2. Closed questions & 9.67 & 8.50 & 7.22 & 8.5 & 2.89 & 5.38 & 4.70 & 5.60 \\
\hline 3. Open questions & 4.04 & 11.30 & 10.74 & 8.73 & 1.24 & 5.86 & 3.5 & 4.49 \\
\hline 4. Restatements & 36.80 & 21.87 & 19.90 & 26.30 & 20.20 & 24.86 & 39.23 & 35.52 \\
\hline 5. Reflection of feelings & 22.37 & 20.90 & 22.54 & 21.83 & 19.43 & 25.57 & 27.65 & .33 \\
\hline Total & 79 & 65 & 62 & 69 & 83 & 83 & 79 & 80 \\
\hline $\begin{array}{l}\text { Probability estimates for } \\
\text { exploration skills }\end{array}$ & .79 & .65 & .62 & & $.83^{*}$ & $.78^{*}$ & $.78^{*}$ & \\
\hline \multicolumn{9}{|l|}{ Insight skills } \\
\hline 6. Challenge & 2.87 & 2.19 & 3.52 & 2.78 & .41 & 1.03 & .66 & .91 \\
\hline 7. Interpretation & 11.69 & 14.20 & 13.20 & 13.10 & 2.72 & 2.93 & 7.21 & 5.22 \\
\hline 8. Self-disclosure & 0 & 0 & 0 & 0 & 0 & 0 & 0 & 0 \\
\hline 9. Immediacy & 1.01 & 2.40 & 1.58 & 1.73 & .59 & .79 & 4.04 & 1.97 \\
\hline Total & 16 & 19 & 18 & 17 & 6 & 5 & 13 & 8 \\
\hline $\begin{array}{l}\text { Probability estimates for } \\
\text { insight skills }\end{array}$ & $.16^{*}$ & $.19^{*}$ & $.18^{*}$ & & .07 & .06 & .12 & \\
\hline \multicolumn{9}{|l|}{ Action skills } \\
\hline 10. Information & 5.34 & 4.98 & 10.21 & 6.53 & 4.43 & .95 & 4.59 & 4.52 \\
\hline 11. Direct guidance & .29 & 10.80 & 7.92 & 6.38 & .76 & 11.48 & 4.37 & 6.94 \\
\hline Total & 5 & 15 & 18 & 13 & 10 & 12 & 7 & 11 \\
\hline $\begin{array}{l}\text { Probability estimates for } \\
\text { action skills }\end{array}$ & .06 & .15 & $.18^{*}$ & & $.09^{*}$ & .15 & .09 & \\
\hline
\end{tabular}

* Statistically significant difference at the $p<.05$ level in inter-group comparison on the same phase. 
variables have a linear effect on the probability through a link function (i.e., a logarithmic function that allows outcomes to be between 0 and 1 ). The explanatory variables (type of outcome and therapy phase) were then included to arrive at a vector of the parameters (probabilities of each therapist skill). When fitting the data to this model, we ended up with the selected linear model (adjusted for each skill type), as shown in the following equation (using exploration skills as the example):

Probability (of exploration interventions | explanatory variables)

$$
=\frac{\exp \left(\mathrm{L}_{1}\right)}{\sum_{\mathrm{i}=1}^{4} \mathrm{~L}_{\mathrm{i}}}
$$

where,

$$
\begin{aligned}
L_{1}= & \beta_{1} \text { If }(\text { poor outcome })+\beta_{2} \text { If }(\text { good outcome }) \\
& +\beta_{3} \text { If }(\text { poor outcome }, \text { middle phase }) \\
& +\beta_{4} \text { If }(\text { poor outcome }, \text { final phase }) \\
& +\beta_{5} \text { If }(\text { good outcome }, \text { middle phase }) \\
& +\beta_{6} \text { If }(\text { good outcome }, \text { final phase }) .
\end{aligned}
$$

( $\beta=\left(\beta_{1}, \beta_{2}, \beta_{3}, \beta_{4}, \beta_{5}, \beta_{6}\right)$ is the vector of the parameters to estimate).

In this model, we contrasted the probability of exploration and action skills against the insight skills category (insight was used as contrast for convenience because in this method, one category had to be always contrasted to another).

Results indicated that exploration skills were used significantly more often, whereas insight skills were used significantly less often in GO than PO cases in all phases of therapy (see Table 4). In contrast, action skills were used significantly more often in the initial phase of GO than PO cases, but significantly more often in the final phase of PO than GO cases.

\section{The Association Between Therapist Skills and Overall IMs}

Table 5 shows the distribution of IMs across the three phases of GO and PO EFT cases. The means and standard deviation of IMs present in the GO cases show that this is a homogenous group. In turn, in the PO group, one of the cases (case 4) exhibits higher amount of IMs than the other two cases. Yet, as these differences are related only to the final phase of PO EFT (where case 4 shows an increased presence of IMs), we consider that these three cases are relatively comparable, being this group moderately homogenous. Furthermore, the marked contrast between the groups at the level of IMs' distribution guarantees the possibility of treating these six cases as two separate groups for the analysis presented in the following section.

Table 6 shows the proportion of skills followed by IMs or non-IMs (i.e., the skill is not followed by an IM in the next client turn) along the initial, middle, and final phases of GO and PO outcome groups. We did sequential analyses of how often an IM (of any type) followed or did not follow each of the three types of therapist skills but, as we were interested in studying only innovation (i.e., occurrence of IMs), we chose not to report here the results concerning non-IMs. For this, we used a binomial generalized linear mixed (GLM) effects model (Agresti, 2002) to estimate the probability of IMs following the three therapist skills (exploration, insight, action) according to therapy phase (initial, middle, final) and type of outcome (GO or PO). In this GLM, we considered the binary response of IM occurring or not occurring as a random variable with Bernoulli distribution to make an inference on the probability parameter associated to this distribution. We also used a subject-specific random effect to take variability among individuals into account. We assumed that the probability of an IM occurring was a conditional function of type of outcome, therapist skill, and therapy phase, where the explanatory variables have a linear effect on the probability, through a link function. The explanatory variables (type of outcome, therapist skills, and therapy phase) were included to arrive at a vector of the parameters (probability of an IM occurring). We ended up with the selected linear model (which includes only the significant variables), using the following equation (where $b$ is the vector of the parameters to estimate):

\begin{tabular}{|c|c|c|c|c|c|}
\hline \multirow[b]{2}{*}{ Outcome status } & \multirow[b]{2}{*}{ Clients } & \multicolumn{4}{|c|}{ Percentages of innovative moments } \\
\hline & & Initial phase $\%$ & Middle phase $\%$ & Final phase $\%$ & Total \% \\
\hline \multirow[t]{4}{*}{ Good outcome } & 1 & 25.80 & 47.70 & 34.70 & 37.60 \\
\hline & 2 & 10.90 & 37.10 & 53.60 & 32.30 \\
\hline & 3 & 13.60 & 27.50 & 60.10 & 33.00 \\
\hline & Overall means of IMs $(S D)$ & $16.77(7.94)$ & $37.43(10.10)$ & $49.47(13.19)$ & $34.30(2.88)$ \\
\hline \multirow[t]{4}{*}{ Poor outcome } & 4 & 9.90 & 19.60 & 34.60 & 18.10 \\
\hline & 5 & .90 & 18.20 & 5.30 & 7.30 \\
\hline & 6 & 2.60 & 16.20 & 1.20 & 6.90 \\
\hline & Overall means of IMs $(S D)$ & $4.47(4.78)$ & $18.00(1.71)$ & $13.70(18.21)$ & $10.77(6.35)$ \\
\hline
\end{tabular}

$$
\text { Probability (of IM } \mid \text { explanatory variables) }=\frac{\exp (\theta)}{1+\exp (\theta)}
$$

where

$$
\begin{aligned}
\theta= & \beta_{1} \text { If (poor outcome) } \\
& +\beta_{2} \text { If (good outcome) } \\
& +\beta_{3} \text { If (poor outcome, middle phase) } \\
& +\beta_{4} \text { If (poor outcome, final phase) }
\end{aligned}
$$

Table 5

Distribution of IMs Across the Three Phases of Therapy in Good and Poor Outcome Cases 
Table 6

Association Between Therapist Skills and Total IMs in Good and Poor Outcome Groups

\begin{tabular}{|c|c|c|c|c|c|c|}
\hline \multirow[b]{2}{*}{ Phase } & \multicolumn{3}{|c|}{ Poor outcome } & \multicolumn{3}{|c|}{ Good outcome } \\
\hline & $\begin{array}{l}\text { Exploration } \\
\text { intervention }\end{array}$ & $\begin{array}{c}\text { Insight } \\
\text { intervention }\end{array}$ & $\begin{array}{l}\text { Action } \\
\text { intervention }\end{array}$ & $\begin{array}{l}\text { Exploration } \\
\text { intervention }\end{array}$ & $\begin{array}{l}\text { Insight } \\
\text { intervention }\end{array}$ & $\begin{array}{c}\text { Action } \\
\text { intervention }\end{array}$ \\
\hline \multicolumn{7}{|l|}{ Initial } \\
\hline Followed by IMs & 20 & 1 & 0 & 145 & 12 & 6 \\
\hline Not followed by IMs & 526 & 107 & 39 & 630 & 41 & 82 \\
\hline $\begin{array}{l}\text { Probability estimates of } \\
\text { IM occurring }\end{array}$ & .03 & .04 & .03 & $.17^{*}$ & $.24^{*}$ & $.15^{*}$ \\
\hline \multicolumn{7}{|l|}{ Middle } \\
\hline Followed by IMs & 83 & 38 & 27 & 298 & 28 & 74 \\
\hline Not followed by IMs & 278 & 117 & 100 & 500 & 32 & 66 \\
\hline $\begin{array}{l}\text { Probability estimates of } \\
\text { IM occurring }\end{array}$ & $.17^{\dagger}$ & $.23^{\dagger}$ & $.15^{\dagger}$ & $.39^{*, \dagger}$ & $.49^{* \dagger}$ & $.36^{*, \dagger}$ \\
\hline \multicolumn{7}{|l|}{ Final } \\
\hline Followed by IMs & 22 & 3 & 3 & 343 & 71 & 20 \\
\hline Not followed by IMs & 81 & 101 & 100 & 381 & 38 & 62 \\
\hline $\begin{array}{l}\text { Probability estimates of } \\
\text { IM occurring }\end{array}$ & $.05^{\dagger}$ & $.07^{\dagger}$ & $.04^{\dagger}$ & $.46^{*}$ & $.56^{* \dagger}$ & $.43^{*}$ \\
\hline
\end{tabular}

${ }^{*}$ Statistically significant difference at the $p<.05$ level in inter-group comparison on the same phase. ${ }^{\dagger}$ Statistically significant difference at the $p<.05$ level in intragroup comparison to the previous phase.

$$
\begin{aligned}
& +\beta_{5} \text { If (good outcome, middle phase) } \\
& +\beta_{6} \text { If (good outcome, final phase) } \\
& +\beta_{7} \text { If (Exploration intervention) } \\
& +\beta_{8} \text { If (Action intervention) }
\end{aligned}
$$

$\left(\beta=\left(\beta_{1}, \beta_{2}, \beta_{3}, \beta_{4}, \beta_{5}, \beta_{6}, \beta_{7}, \beta_{8}\right)\right.$ is the vector of the parameters to estimate).

The estimated probabilities of IMs following each skill category are shown in Table 6 and Figure 1. IMs more often followed skills in GO than PO cases, although there were no differences between the three types of skills and the production of IMs across all phases in either the GO or PO cases. In terms of phase of therapy for the GO cases, IMs more often followed skills in the middle and final phases than in the initial phase. That is, the association of skills with IMs increased from the initial to the middle phase in GO cases, and then maintained the same level from the middle to the final phase. In contrast, in PO cases, the association of skills with IMs increased from the initial to the middle phase of therapy, but then decreased from the middle to the final phase, demonstrating a higher occurrence of IMs in the middle phase of PO cases (see Figure 1).

\section{The Association Between Therapist Skills and Different Types of IMs}

We also investigated the probabilities of specific types of IMs following specific therapist skills in the three phases for the two outcome groups. For this analysis, we combined action, reflection,
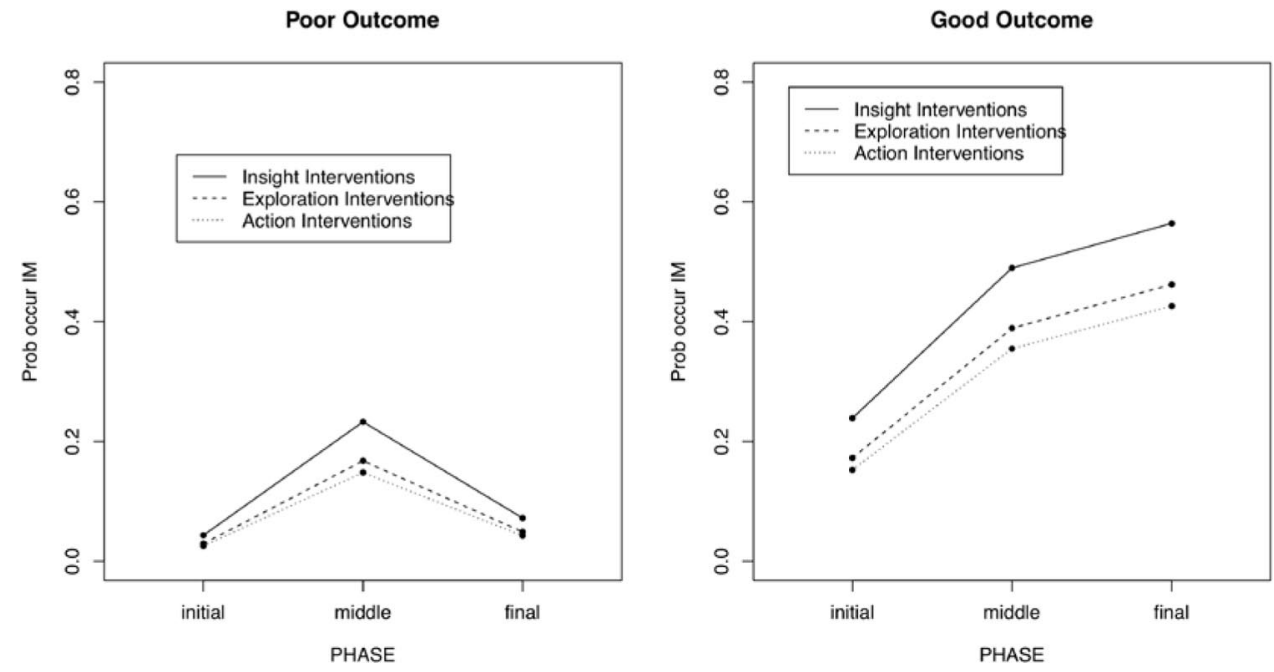

Figure 1. Probability of an IM occurring after each therapist skill. 
and protest IMs into a new category that we called ARP IMs, whereas reconceptualization and performing change IMs were combined into a second new category that we called RCPC IMs. We chose to adopt a less specific analysis regarding the types of IMs because some of the types had very low presence (according to the previous study by Mendes et al., 2010) and also because of the role that action, reflection, and protest IMs in contrast with reconceptualization and performing change IMs seem to play in narrative change (elaborated upon previously in the text).

For this analysis, we used a multinomial GLM mixed effects model (Agresti, 2002) to estimate the probability of the occurrence of ARP IMs versus RCPC IMs according to skills (exploration, insight, action), therapy phase (initial, middle, final) and type of outcome (GO or PO). We used the same model for the expected value as was used for the previous model of overall IMs, with two additional probabilities to estimate the occurrence of ARP or RCPC IMs at each phase for each outcome:

Probability (occurring ARP IMs | explanatory variables)

$$
=\frac{\exp \left(\theta_{1}\right)}{1+\exp \left(\theta_{1}\right)+\exp \left(\theta_{2}\right)}
$$

Probability (occurring RCPC IMs | explanatory variables)

$$
=\frac{\exp \left(\theta_{1}\right)}{1+\exp \left(\theta_{1}\right)+\exp \left(\theta_{2}\right)}
$$

The results are shown in Table 7 and Figure 2. Overall, both ARP IMs and RCPC IMs followed skills more often in GO than PO cases for all phases of therapy. In the GO cases in both the initial and middle phase, all three skills were more often associated with ARP IMs than RCPC IMs. In the final phase of GO cases, exploration and insight were more often associated with RCPC IMs than ARP IMs, whereas action skills were more often associated with ARP IMs than RCPC IMs. In the PO cases, a significant difference emerged only in the final phase: all skills were more often associated with ARP IMs than with RCPC IMs.

\section{Discussion}

In this study of the association between therapist skills and IMs for EFT of depression, we found that exploration, insight, and action skills all preceded IMs more often in GO than PO cases, suggesting that these skills had more impact on GO than on PO cases. Regarding the phases of treatment, the association between skills and IMs in GO cases increased from the initial to the middle phase and maintained the same level from the middle to final phase. In contrast, in PO cases, the association increased from the initial to middle phase, but then decreased from the middle to final phase. These results suggest that the middle phase of therapy is particularly important as a working phase of EFT in both GO and PO cases, but in GO cases, the productivity of skills is maintained from the middle to the final phase, unlike what occurs in PO cases. In the next sections, we explore further the results for the exploration, insight, and action skills.

\section{Exploration Skills}

The vast majority of skills used in both GO and PO cases were exploration skills, suggesting that exploration skills are preferred more than insight and action skills by EFT therapists. These findings are consistent with the empirical literature (e.g., Elliott et al., 2004) and the client-centered stance of EFT (Greenberg, 2006; Greenberg, Rice, \& Elliott, 1993; Pos \& Greenberg, 2007).

Although exploration skills occurred more frequently than insight and action skills, they were no more likely to lead to overall IMs. However, exploration (and insight) skills preceded ARP IMs more often than RCPC IMs in the initial and middle phases, but more often preceded RCPC IMs than ARP IMs in the final phase of GO cases. This finding is consistent with the theoretical model of change presented in the introduction of this article (see also Gonçalves et al., 2009), given that ARP IMs are typical of the initial and middle stages of treatment, whereas RCPC IMs are more typical of middle and final stages of GO cases and, as these findings show, are mainly produced by exploration (and insight skills) in the final treatment phase. Exploration skills may elicit the more complex IMs only later in therapy once the foundation has been set with the simpler IMs (i.e., action, reflection, and protest). Therefore, the current findings highlight the importance of exploration skills in GO cases of EFT, which is consistent with the assumptions of this therapy.

Table 7

\begin{tabular}{|c|c|c|c|c|c|c|}
\hline \multirow[b]{2}{*}{ Phase } & \multicolumn{3}{|c|}{ Poor outcome } & \multicolumn{3}{|c|}{ Good outcome } \\
\hline & $\begin{array}{l}\text { Exploration } \\
\text { intervention }\end{array}$ & $\begin{array}{c}\text { Insight } \\
\text { intervention }\end{array}$ & $\begin{array}{c}\text { Action } \\
\text { intervention }\end{array}$ & $\begin{array}{l}\text { Exploration } \\
\text { intervention }\end{array}$ & $\begin{array}{c}\text { Insight } \\
\text { intervention }\end{array}$ & $\begin{array}{c}\text { Action } \\
\text { intervention }\end{array}$ \\
\hline \multicolumn{7}{|l|}{ Initial } \\
\hline Probability of ARP IMs & .03 & .04 & .03 & $.16^{*}$ & $.19^{*, \dagger}$ & $.18^{*, \dagger}$ \\
\hline Probability of RCPC IMs & .00 & .00 & .00 & $.02^{*}$ & $.03^{*}$ & $.002^{*}$ \\
\hline \multicolumn{7}{|l|}{ Middle } \\
\hline Probability of ARP IMs & .17 & .21 & .19 & $.28^{*, \dagger}$ & $.29^{*, \dagger}$ & $.34^{*, \dagger}$ \\
\hline Probability of RCPC IMs & .00 & .00 & .00 & $.11^{*, \dagger}$ & $.21^{*, \dagger}$ & $.02^{*, \dagger}$ \\
\hline \multicolumn{7}{|l|}{ Final } \\
\hline Probability of ARP IMs & $.04^{\dagger}$ & $.05^{\dagger}$ & $.05^{\dagger}$ & $.18^{*, \dagger}$ & $.16^{*, \dagger}$ & $.26^{*}$ \\
\hline Probability of RCPC IMs & $.03^{\dagger}$ & $.01^{\dagger}$ & $.00^{\dagger}$ & $.29^{* \dagger}$ & $.46^{*, \dagger}$ & $.07^{*}$ \\
\hline
\end{tabular}

The Association Between Therapist Skills and ARP IMs and RCPC IMs

* Statistically significant difference at the $p<.05$ level in inter-group comparison to the same phase. ${ }^{\dagger}$ Statistically significant difference at the $p<.05$ level in intragroup comparison between APR IMs and RCPC IMs. 

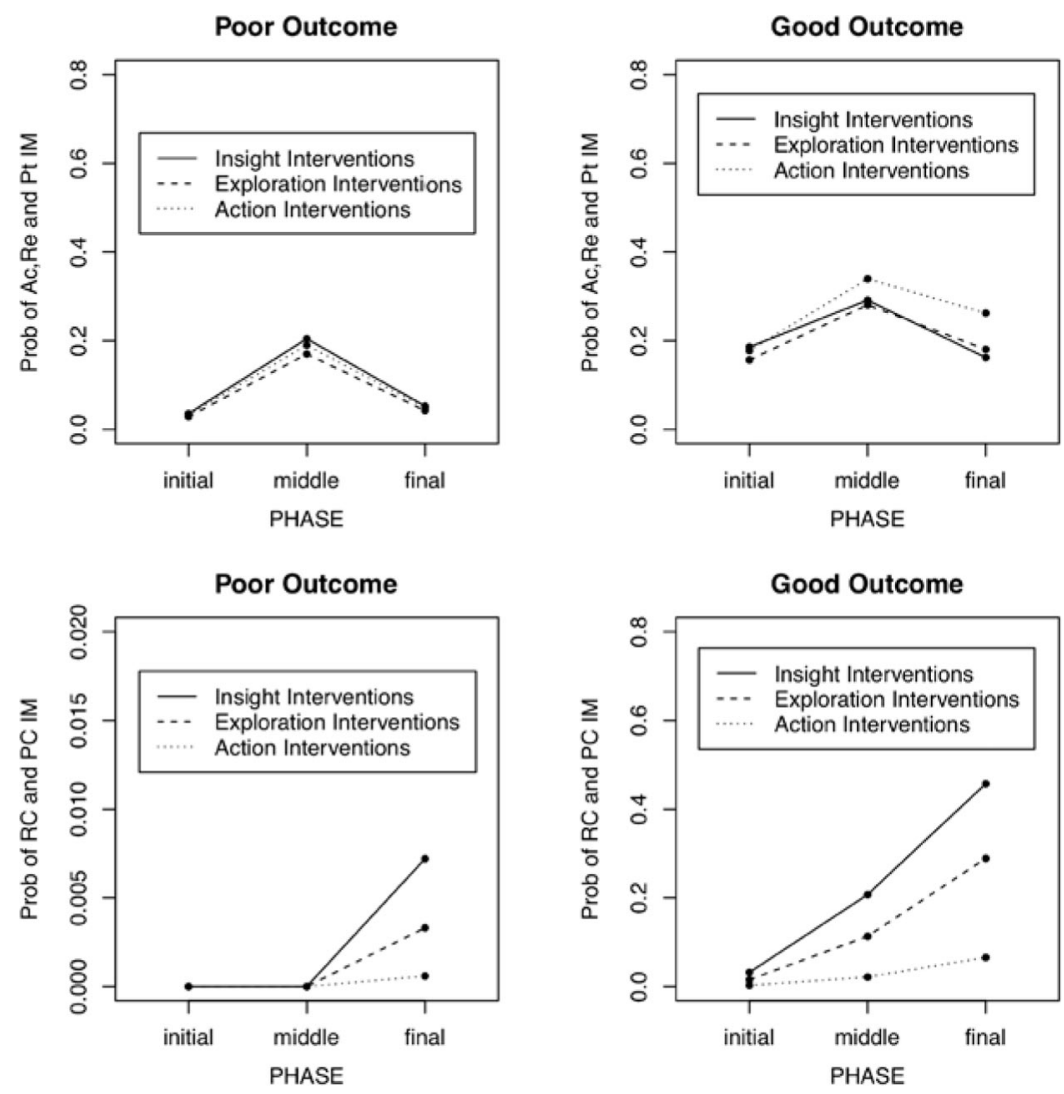

Figure 2. Probabilities of therapist skills on ARP IMs and RCPC IMs.

\section{Insight Skills}

Insight skills were used far less often than exploration skills, reflecting EFT therapists' preference for not offering insight to their clients. Moreover, insight skills were used more often in all phases of PO (16\%-19\%) in contrast with GO cases $(6 \%-13 \%)$. We speculate that in PO cases, therapists were trying to find some way to help the clients when the more typically prescribed exploration skills were not working.

In addition, as described previously, insight skills functioned similarly to exploration skills in terms of being associated with different types of IMs in the three phases of EFT. That is, they also appeared to be linked to the production of ARP IMs in the initial and middle phases and to the production of RCPC IMs in the final phase of therapy. Although EFT theorists downplayed the role of insight skills, the current findings suggest that insight may be important also in experiential therapies such as EFT (see also Castonguay \& Hill, 2007). According to this view, Pascual-Leone and Greenberg (2007) have acknowledged that the promotion of specific types of insight (i.e., experiential insight) may be an important dimension of change in experiential therapies.

\section{Action Skills}

In GO cases, action skills were used about $10 \%$ to $12 \%$ of the time in the initial and middle phases but used only $7 \%$ of the time in the final phases of GO cases. We speculate that action skills were used more often at the beginning and middle phases of GO cases because the therapists and clients were engaging actively in EFT tasks such as empty chair work. But as therapy wound down, therapists may have shifted away from this intense directive work and instead moved to helping clients consolidate their gains. In contrast, in the PO cases, action steadily increased $(5 \%, 15 \%, 18 \%)$ across phases. We speculate that therapists in the PO cases were not able to engage clients as readily in the therapeutic tasks and kept trying to engage them when it may have been too late.

Furthermore, action skills were more often associated with the simpler action, reflection, and protest IMs rather than the more complex reconceptualization and performing change IMs in GO cases. This association is especially clear in the final phase of therapy, suggesting that the emergence of IMs still continues to be important at this stage. We suggested in the Introduction that the simpler and more complex IMs interact, further stimulating the occurrence of the more complex IMs. That is, as clients narrate a different story of themselves (reconceptualization and performing change IMs), specific actions, thoughts, and feelings (action, reflection, and protest IMs) that are congruent with the former still occur and further contribute to the change. However, although action skills can be used to facilitate more simple IMs (i.e., action, reflection, and protest), they seem less efficient in helping clients attain the more complex IMs (i.e., reconceptualization and performing change). Thus, although EFT therapists use action skills to 
direct clients to engage in therapeutic tasks especially within the initial and middle phases of therapy, it appears that they also need to use exploration and insight skills to promote the more complex IMs later in therapy.

\section{Implications for Practice, Training, and Future Research}

In terms of practice and training, these findings suggest the crucial need for therapists to pay attention to the immediate outcomes of their specific interventions, to note, for example, whether their exploration, action, and insight skills indeed occur before client IMs. Another interesting direction for future studies would be to carry out an intensive analysis of the specific skills (interpretations, challenges, and immediacy) that constitute this category to see if the way these are used by EFT therapists contrasts with the way they are used in other therapeutic models (see Gazzola \& Stalikas, 1997). Thus, training could provide a skillful detection and differentiation of skills used and types of IMs.

If EFT therapists are interested in promoting client IMs (such as action, reflection, and protest), in the initial and middle phases of therapy, or more complex types of IMs in the final phase of EFT (such as reconceptualization and performing change), the use of exploration skills would probably be more helpful and safe (in terms of the facilitation of IMs as immediate outcomes). Thus, therapists can adhere to a humanistic supportive stance and accentuate the clients' frame of reference and allow therapeutic movement by following the clients' pace to set the foundation of narrative change in the initial and middle phases of therapy (associated with the emergence of action, reflection, and protest IMs) and expand narrative change in later stages of therapy (associated with reconceptualization and performing change IMs).

Although probably less frequently, EFT therapists can also use the more directive action skills to promote narrative changes, given that action skills were associated with action, reflection, and protest IMs during all therapy phases of GO therapy. Even though these types of skills, related to the more active EFT interventions, may become less important at later stages of GO cases, they may provide a useful tool to assess if the EFT process is developing as it should. In other words, noting how clients react to action skills may help therapists predict the therapeutic outcome of their clients at midtreatment, such that a better outcome can probably be expected if clients respond with IMs. Contrastingly, if clients fail to engage in more active interventions in the earlier stages phase of treatment and do not respond to these with IMs, a poorer outcome may occur.

We are less able to offer suggestions about the use of insight skills in EFT, given our results. Taking into account only the GO cases, we might say that their use is as helpful as exploration skills, even though EFT therapists use insight much less than exploration. However, taking into account that these skills are indeed more often used in PO than in GO cases, we conclude that a higher use of insight skills is not necessarily better in terms of narrative change in EFT. These findings suggest that a limited but accurate use of insight skills is beneficial, whereas a high usage could be unproductive in terms of IMs. Of course, the clients' response to insight skills may be dependent on their readiness to change. In other words, if clients are more open or ready to change (like GO clients usually are), they might respond better to insight (and exploration) skills with IMs. But if clients are less ready to change, therapists might be more tempted to push for change through the use of insight skills, and the immediate results of this may be poorer (than in GO clients).

Future training of therapists could focus more intensively on the distinction between insight and exploration skills, a suggestion also highlighted previously by Hill and Kellems (2002). Furthermore, researchers could examine the insight skills used in EFT to highlight their role and explore more intensively how the findings related to these skills might cohere with the EFT model. A possible avenue for research could also be to study the contrast between more traditional forms of promoting insight in therapy and the promotion of experiential insight in EFT.

In our view, it would be interesting to extend these findings to additional GO and PO clients of EFT and also to other cases from different theoretical approaches and client types. It would also be interesting to expand the study to longer sequences of interaction, beyond one lag (i.e., immediate client turn) to determine whether the occurrence of IMs might occur at longer lags.

\section{Limitations of the Present Study}

The first major limitation is the small sample of six cases chosen to represent good and poor EFT cases. Because these cases represent only five therapists all trained by the developers of EFT, results may not generalize to other therapists. And the findings are limited to clients who have depression and who are willing to participate in research.

The second limitation regarding this sample is that we used heterogeneous contrasting groups: the two outcome groups (composed of the six clients) initiated EFT treatment with different levels of depression (i.e., the GO group started with severe depression, whereas the PO started therapy with moderate depression). In the future, contrasting outcome groups could be paired using clients with similar initial depression levels. Furthermore, although the sample of GO clients was very homogenous in terms of narrative change, the sample of PO clients was only moderately homogeneous. Future studies should account for this variability in terms of narrative change.

The third limitation is that the system for coding therapist skills is pantheoretical rather than having been developed specifically for EFT. In this sense, it may not be sensitive to highlighting the unique skills used in EFT (see Elliot et al., 2004, for details about a coding system developed specifically for EFT) and may account for the unexpected findings regarding the association between insight skills and IMs. However, we would argue that using a pantheoretical system is important for producing results that apply to all therapeutic approaches.

Fourth, we are also aware that the use of this research design does not acknowledge that in therapy, as in human interactions in general, communication is mutually responsive (i.e., bidirectional) to the people involved in a given situation (Gordon \& Toukmanian, 2002; Stiles, Honos-Webb, \& Surko, 1998). Thus, the use of more insight skills by EFT therapists in the PO group might be a consequence of limited responsiveness to change by these clients. Still, this study yielded findings that can be useful as long as we recognize that they represent only one dimension and one direction of therapist and client talk, abstracted from the multilayered phe- 
nomena of therapeutic interaction (De Stefano, Bernardelli, Stalikas, \& Iwakabe, 2001; Hill, 2005).

\section{References}

Agresti, A. (2002). Categorical data analysis (2nd ed.). New York, NY: Wiley. doi:10.1002/0471249688

Angus, L., \& Mcleod, J. (Eds.). (2004). The handbook of narrative psychotherapy: Practice, theory and research. London, UK: Sage.

Angus, L. E., \& Greenberg, L. S. (2011). Working with narrative in emotion-focused therapy: Changing stories, healing lives. Washington, DC: American Psychological Association.

Auld, F., \& White, A. M. (1956). Rules for dividing interviews into sentences. Journal of Psychology: Interdisciplinary and Applied, 42, 273-281. doi:10.1080/00223980.1956.9713040

Barkham, M., \& Shapiro, D. A. (1986). Counselor verbal response modes and experienced empathy. Journal of Counseling Psychology, 33, 3-10. doi:10.1037/0022-0167.33.1.3

Beck, A. T., Steer, R. A., \& Garbin, M. G. (1988). Psychometric properties of the Beck Depression Inventory: Twenty-five years of evaluation. Clinical Psychology Review, 8, 77-100. doi:10.1016/02727358(88)90050-5

Beck, A. T., Ward, C. H., Mendelson, M., Mock, J., \& Erbaugh, J. (1961). An inventory for measuring depression. Archives of General Psychiatry, 4, 561-571. doi:10.1001/archpsyc.1961.01710120031004

Boritz, T. Z., Angus, L., Monette, G., \& Hollis-Walker, L. (2008). An empirical analysis of autobiographical memory specificity subtypes in brief emtion-focused and client-centered treatments of depression. Psychotherapy Research, 18, 584-593. doi:10.1080/10503300802123245

Boritz, T. Z., Angus, L., Monette, G., Hollis-Walker, L., \& Warwar, S. (2011). Narrative and emotion integration in psychotherapy: Investigating the relationship between autobiographical memory specificity and expressed emotional arousal in brief emotion-focused and client-centred treatments of depression. Psychotherapy Research, 21, 16-26.

Botella, L., Herrero, O., Pacheco, M., \& Corbella, S. (2004). Working with narrative in psychotherapy: A relational constructivist approach. In L. E. Angus \& J. McLeod (Eds.), The handbook of narrative and psychotherapy: Practice, theory, and research (pp. 119-1136). Thousand Oaks, CA: Sage

Castonguay, L., \& Hill, C. E. (Eds.). (2007). Insight in psychotherapy. Washington, DC: American Psychological Association. doi:10.1037/ 11532-000

De Stefano, J., Bernardelli, A., Stalikas, A., \& Iwakabe, S. (2001). The relationship of therapist verbal response mode and client good moments in short term dynamic psychotherapy. Canadian Journal of Counselling [Revue Canadienne de Counseling], 35, 260-276.

Dimaggio, G., Salvatore, G., Azzara, C., \& Catania, D. (2003). Rewriting self-narratives: The therapeutic process. Journal of Constructivist Psychology, 16, 155-181. doi:10.1080/10720530390117920

Elliot, R., Greenberg, L. S., \& Lietaer, G. (2004). Research on experiential psychotherapies. In M. J. Lambert (Ed.), Bergin and Garfield's handbook of psychotherapy and behavior change (pp. 493-539). New York, NY: John Wiley \& Sons.

Elliott, R., Hill, C. E., Stiles, W. B., Friedlander, M. L., Mahrer, A. R., \& Margison, F. R. (1987). Primary therapist response modes: Comparison of six rating systems. Journal of Counseling Psychology, 55, 218-223. doi:10.1037/0022-006X.55.2.218

Elliott, R. (1985). Helpful and nonhelpful events in brief counseling interviews: An empirical taxonomy. Journal of Counseling Psychology, 32, 307-322. doi:10.1037/0022-0167.32.3.307

Elliott, R. (2010). Psychotherapy change process research: Realizing the promise. Psychotherapy Research, 20, 123-135. doi:10.1080/ 10503300903470743

Fitzpatrick, M. R., Stalikas, A., \& Iwakabe, S. (2001). Examining coun- selor interventions and client progress in the context of the therapeutic alliance. Psychotherapy: Theory, Research, Practice, Training, 38, 160 170. doi: $10.1037 / 0033-3204.38 .2 .160$

Gazzola, N., \& Stalikas, A. (1997). An investigation of counselor interpretations in client-centered therapy. Journal of Psychotherapy Integration, 7, 313-327. doi:10.1023/B:JOPI.0000010886.33685.64

Gazzola, N., \& Stalikas, A. (2004). Therapist interpretations and client processes in three therapeutic modalities: Implications for psychotherapy integration. Journal of Psychotherapy Integration, 14, 397-418.

Gelso, C. J. (Ed.). (2005). The interplay of techniques and the therapeutic relationship. Psychotherapy: Theory, Research, Practice, Training, 42, 419-420. doi:10.1037/0033-3204.42.4.419

Goates-Jones, M. K., Hill, C. E., Stahl, J., \& Doschek, E. (2009). Therapist response modes in the exploration stage: Timing and effectiveness. Counselling Psychology Quarterly, 22, 221-231. doi:10.1080/ 09515070903185256

Goldfried, M. R., \& Davila, J. (2005). The role of relationship and technique in therapeutic change. Psychotherapy: Theory, Research, Practice, Training, 42, 421-430. doi:10.1037/0033-3204.42.4.421

Gonçalves, M. M., Matos, M., \& Santos, A. (2009). Narrative therapy and the nature of "innovative moments" in the construction of change. Journal of Constructivist Psychology, 22, 1-23. doi:10.1080/ 10720530802500748

Gonçalves, M. M., Mendes, I., Cruz, G., Ribeiro, A. P., Sousa, I. Angus, L., \& Greenberg, L. S. (In press). Narrative change in client-centered and emotion-focused therapy. Psychotherapy Research.

Gonçalves, M. M., Mendes, I., Ribeiro, A., Angus, L., \& Greenberg, L. S. (2010). Innovative moments and change in emotional focused therapy: The case of Lisa. Journal of Constructivist Psychology, 23, 1-28. doi:10.1080/10720537.2010.489758

Gonçalves, M. M., Ribeiro, A., Mendes, I., Matos, M., \& Santos, A (2011). Tracking novelties in psychotherapy process research: The Innovative Moments Coding System. Psychotherapy Research, 21, $497-$ 509. doi:10.1080/10503307.2011.560207

Gonçalves, M. M., \& Stiles, W. B. (2011). Introduction to the special section on narrative and psychotherapy. Psychotherapy Research, 21 , 1-3. doi:10.1080/10503307.2010.534510

Gordon, K. M., \& Toukmanian, S. G. (2002). Is how it is said important? The association between quality of therapist interventions and clien processing. Conselling and Psychotherapy Research, 2, 88-98. doi: 10.1080/14733140212331384867

Greenberg, L. S., Rice, L. N., \& Elliott, R. (1993). Facilitating emotional change: The moment-by-moment process. New York, NY: The Guilford Press.

Greenberg, L. S., \& Watson, J. (1998). Experiential therapy of depression: Differential effects of client-centred relationship conditions and process interventions. Psychotherapy Research, 8, 210-224.

Greenberg, L., \& Angus, L. (2004). The contributions of emotion processes to narrative change in psychotherapy: A dialectical constructivist approach. In L. Angus \& J. McLeod (Eds.), Handbook of narrative psychotherapy: Practice, theory, and research (pp. 331-349). Thousand Oaks, CA: Sage.

Greenberg, L. S. (2006). Emotion focused therapy: A synopsis. Journal of Contemporary Psychotherapy, 36, 87-93. doi:10.1007/s10879-0069011-3

Hess, S. A., Knox, S., \& Hill, C. E. (2006). Teaching graduate trainees how to manage client anger: A comparison of three types of training. Psychotherapy Research, 16, 282-292. doi:10.1080/10503300500264838

Hill, C. E., Nutt, E. A., \& Jackson, S. (1994). Trends in psychotherapy process research: Samples, measures, researchers, and classic publications. Journal of Counseling Psychology, 42, 364-377.

Hill, C. E., \& Kellems, I. S. (2002). Development and use of the helping skills measure to assess client perceptions of the effects of training and 
of helping skills in sessions. Journal of Counseling Psychology, 49, 264-272. doi:10.1037/0022-0167.49.2.264

Hill, C. E., \& Lambert, M. J. (2004). Methodological issues in studying psychotherapy processes and outcomes. In M. J. Lambert, (Ed.), Bergin and Garfield's Handbook of psychotherapy and behavior change (5th ed., pp. 84-135). New York, NY: John Wiley \& Sons, Inc.

Hill, C. E., \& Lent, R. W. (2006). A narrative and meta-analytic review of helping skills training: Time to revive a dormant area of inquiry. Psychotherapy: Theory, Research, Practice, Training, 43, 154-172. doi: 10.1037/0033-3204.43.2.154

Hill, C. E., Thames, T. B., \& Rardin, D. K. (1979). Comparison of Rogers, Perls, and Ellis on the Hill counselor verbal response category system. Journal of Counseling Psychology, 26, 198-203. doi:10.1037/00220167.26.3.198

Hill, C. E., Thompson, B. J., \& Williams, E. N. (1997). A guide to conducting consensual qualitative research. The Counseling Psychologist, 25, 517-572. doi:10.1177/0011000097254001

Hill, C. E. (1978). Development of a counselor verbal response category system. Journal of Counseling Psychology, 25, 461-468. doi:10.1037/ 0022-0167.25.5.461

Hill, C. E. (1986). An overview of the Hill counselor and client verbal response modes category systems. In L. S. Greenberg \& W. M. Pinsof (Eds.), The psychotherapeutic process: A research handbook (pp. 131159). New York, NY: Guilford Press.

Hill, C. E. (2005). Therapist techniques, client involvement, and the therapeutic relationship: Inextricably intertwined in the therapy process. Psychotherapy: Theory, Research, Practice, Training, 42, 431-442. doi:10.1037/0033-3204.42.4.431

Hill, C. E. (2009). Helping skills: Facilitating exploration, insight, and action (3rd ed.). Washington, DC: American Psychological Association.

Honos-Webb, L., Stiles, W. B., \& Greenberg, L. S. (2003). A method for rating assimilation in psychotherapy based on markers of change. Journal of Counseling Psychology, 50, 189-198. doi:10.1037/00220167.50.2.189

Honos-Webb, L., Surko, M., Stiles, W. B., \& Greenberg, L. S. (1999). Assimilation of voices in psychotherapy: The case of Jan. Journal of Counseling Psychology, 46, 448-460. doi:10.1037/0022-0167.46.4.448

Jacobson, N. S., \& Truax, P. (1991). Clinical significance: A statistical approach to defining meaningful change in psychotherapy research. Journal of Consulting and Clinical Psychology, 59, 12-19. doi:10.1037/ 0022-006X.59.1.12

Levitt, H., Korman, L., \& Angus, L. (2000). A metaphor analysis in treatments of depression: Metaphor as a marker of change. Counseling Psychology Quarterly, 13, 23-36. doi:10.1080/09515070050011042

Matos, M., Santos, A., Gonçalves, M. M., \& Martins, C. (2009). Innovative moments and change in narrative therapy. Psychotherapy Research, 19, 68-80. doi:10.1080/10503300802430657

McGlinchey, J. B., Atkins, D. C., \& Jacobson, N. S. (2002). Clinical significance methods: Which one to use and how useful are they? Behavior Therapy, 33, 529-550. doi:10.1016/S0005-7894(02)80015-6

Mendes, I., Ribeiro, A. P., Angus, L., Greenberg, L., Gonçalves, M. M. (2011). Narrative change in emotion-focused psychotherapy: A study on the evolution of reflection and protest innovative moments. Psychotherapy Research, 21, 304-315. doi:10.1080/10503307.2011.565489

Mendes, I., Ribeiro, A. P., Angus, L. E., Greenberg, L. S., Sousa, I., \& Gonçalves, M. M. (2010). Narrative change in emotion-focused therapy: How is change constructed through the lens of the innovative moments coding system? Psychotherapy Research, 20, 692-701. doi:10.1080/ 10503307.2010.514960

Pascual-Leone, A., \& Greenberg, L. S. (2007). Insight and awareness in experiential therapy. In L. G. Castonguay \& C. Hill (Eds.), Insight in psychotherapy (pp. 31-56). Washington, DC: American Psychological Association. doi:10.1037/11532-002

Pos, A. E., \& Greenberg, L. S. (2007). Emotion-focused therapy: The transforming power of affect. Journal of Contemporary Psychotherapy, 37, 25-31. doi:10.1007/s10879-006-9031-z

Snyder, W. U. (1945). An investigation of the nature of non-directive psychotherapy. Journal of General Psychology, 33, 193-223.

Stiles, W. B. (1979). Verbal response modes and psychotherapeutic technique. Psychiatry, 42, 49-62.

Stiles, W. B., Honos-Webb, L., \& Surko, M. (1998). Responsiveness in psychotherapy. Clinical Psychology: Science \& Practice, 5, 439-458. doi:10.1111/j.1468-2850.1998.tb00166.x

Stiles, W. B., Shapiro, D. A., \& Firth-Cozens, J. A. (1989). Therapist differences in the use of verbal response mode forms and intents. Psychotherapy, 26, 314-322. doi:10.1037/h0085441

White, M., \& Epston, D. (1990). Narrative means to therapeutic ends. New York, NY: Norton.

White, M. (2007). Maps of narrative practice. New York, NY: Norton.

Received July 21, 2011

Revision received February 16, 2012

Accepted February 27, 2012 